\title{
Bottlenecks to clinical translation of direct brain-computer interfaces
}

\author{
Mijail D. Serruya * \\ Department of Neurology, Thomas Jefferson University, Philadelphia, PA, USA
}

\section{Edited by:}

loan Opris, Wake Forest University, USA

Reviewed by:

Mikhail Lebedev, Duke University, USA

Dong Song, University of Southern California, USA

\section{*Correspondence:}

Mijail D. Serruya, Department of Neurology, Thomas Jefferson University, 901 Walnut Street, Suite 400, Philadelphia, PA 19107, USA e-mail: Mijail.Serruya@jefferson.edu
Despite several decades of research into novel brain-implantable devices to treat a range of diseases, only two-cochlear implants for sensorineural hearing loss and deep brain stimulation for movement disorders-have yielded any appreciable clinical benefit. Obstacles to translation include technical factors (e.g., signal loss due to gliosis or micromotion), lack of awareness of current clinical options for patients that the new therapy must outperform, traversing between federal and corporate funding needed to support clinical trials, and insufficient management expertise. This commentary reviews these obstacles preventing the translation of promising new neurotechnologies into clinical application and suggests some principles that interdisciplinary teams in academia and industry could adopt to enhance their chances of success.

Keywords: brain-computer interface, neurotechnology, device approval, commercialization, neuroprosthetic

\section{INTRODUCTION}

"Brain-computer interfaces" (BCI) and "brain-machine interfaces" (BMI) comprise a class of medical devices designed to restore independent function lost by neurological disease or injury. The qualifier "direct" implies that some component of the artificial device is physically implanted into the brain. While the $\mathrm{BCI}$ terminology usually refers to techniques that sense electrical activity in the brain to determine intended movement with the goal of restoring independent communication and movement in patients with paralysis, in principle any device implanted into the brain that includes electronic components could be considered a BCI, for example systems to detect and arrest seizures (Stacey and Litt, 2008) or to restore episodic memory (Hampson et al., 2013; Sankar et al., 2014). While there has been tremendous interest in BCIs, including several pilot trials in human patients and an explosion of publications in the past few decades, the clinical benefits have remained quite limited. The purpose of this essay is to address the disconnect between hundreds of laboratories around the world toiling on BCIs and the thousands to millions of patients who could benefit from this technology yet are not.

"Motor" BCIs refer to systems that decode intended movement and use this decoded information to control some object in the world: such as a computer to type out text for communication, turn off and on light switches, navigate with a wheelchair, or control one's own body with external powered braces or internal neuromuscular stimulators. Given several decades of work on external scalp-EEG based BCIs and nearly a decade since the first human patient was implanted with a multi-electrode array to decode motor intent (Hochberg et al., 2006; Lebedev, 2014), what are the limitations holding back this promising technology from entering the mainstream for clinical care? Sadly, there is no lack of people paralyzed by spinal cord injury, stroke, brain injury, muscular dystrophy and amyotrophic lateral sclerosis. One possible answer would be to counsel patience: while there are over 300,000 people with sensorineural hearing loss who have been implanted with cochlear implants, it has been over seven decades since Djourno and Eyriès showed in 1957, that an inner ear electrode could elicit sound sensations in a deaf listener (Djourno and Eyries, 1957; Macherey and Carlyon, 2014). Is there any way we can learn from prior mistakes and successes so that the translation cycle may be accelerated to bring these therapies to the clinic faster than seven decades?

\section{TECHNICAL LIMITATIONS INFLAMMATION/GLIOSIS}

Several groups have demonstrated that motor intent can be decoded from the activity of ensembles of neurons recorded by microelectrode arrays implanted into the neocortex of paralyzed people (Hochberg et al., 2012; Collinger et al., 2013). A problem for chronic recording of single units is that the number and quality of recordings fall off with time (Suner et al., 2005; Barrese et al., 2013; Wang et al., 2014). Several explanations have been posited: the foreign body of the array induces a reactive gliosis with scarring or inflammation, the device experiences micromotion relative to the cell bodies it seeks to record quenching signal to noise, or the device itself fails internally such as through mechanical breakage of electrodes or electrolytic changes in surface chemistry altering impedance (Prasad et al., 2014). Certain groups have attempted to address this device-brain interface problem by altering the microscopic geometry or surface chemistry of the devices (Sanchez et al., 2006; Moxon et al., 2007; Sommakia et al., 2009; Frewin et al., 2011; Ceyssens et al., 2013; Edgington et al., 2013) others have attempted to circumvent the problem entirely by focusing analysis on the envelope 
of multi-unit activity or analyzing time series in the frequency domain, rather than requiring single units to be discriminated (Dolan et al., 2009; Flint et al., 2013; Lebedev, 2014; Perge et al., 2014).

\section{CHASING THE NOISE}

For motor BCIs there are two learning systems: the mathematical algorithm that decodes neural activity into motor commands, and the patient's brain itself. Unlike alpha motor neurons in the spinal cord which are "hard-wired" in motor pools to specific sets of skeletal muscles, the relationship of cortical neurons to external muscular and somatosensory features is fluid. If the calibration routines used are too frequent or extreme, then the two learning systems will fail to converge on a decoding-control solution and instead will chase the noise, and the paralyzed patient will not be able make use of the device (Wu et al., 2004). It would be analogous to attempting to learn to ride a bicycle if the laws of physics changed with every attempt to pedal.

\section{CALIBRATION AND TECHNICIANS}

All types of motor BCI, whether non-invasive scalp EEG or direct invasive $\mathrm{BCI}$ with implanted electrodes, require considerable set up and calibration with one or more technicians (Sellers et al., 2010; Taherian et al., 2014). Even in the net-connected age with telemedicine, the burden of daily calibration becomes so onerous as to render the motor BCI unfeasible for widespread clinical application (Rupp, 2014).

\section{CHALLENGING PRECONCEPTIONS PRECONCEPTION: LESS INVASIVE TECHNOLOGY IS SAFER FOR PATIENTS THAN MORE INVASIVE TECHNOLOGY}

Just because a technology does not involve a surgical procedure does not mean it is not risky. The balance of risk and benefit must take into account all aspects of a technology, not simply whether one cuts into the skin. As an example, while the heart can be defibrillated and paced by electrodes worn on the chest, this would be completely impractical for patients to use on a daily basis. The system had to be implanted to make it useful. While motor BCIs may not have proved their utility to an equal degree of implanted cardiac pacemakers, the point is that the focus of device development should be on the overall net utility: the greater the potential benefit, the more a given amount of risk could be taken. In terms of risks, there seems to be significant misunderstanding on the part of non-clinicians about what procedures pose risks to patients and what do not. Relative to other neurosurgical procedures, implantation of tiny microelectrode arrays into the surface cortex is less risky than other common neurosurgical procedure. Likewise, the daily scrubbing of a patient's scalp and attachment of electrode pads has its own risks of skin breakdown and even fatal cellulitis in patients who have limited mobility and may be in a constant state of relative immunocompromise (Rupp, 2014). Patients with quadriplegia invariably already have undergone surgeries and have percutaneous devices, such as tracheostomy tubes attached to ventilators and feeding tubes. It would be more useful and safer for quadriplegic patients if scalp EEG systems could be rendered as implantable systems: for example, subdermal grids with wireless telemetry. A minimally invasive approach would simultaneously address several bottlenecks in application: it would decrease the risk of skin infection from repeated scalp electrode application, it would decrease impedance variability that affects device performance, and it would take out the reliance on an external technician to physically affix the electrodes every day to afford useful communication. Conclusion: "Degree of invasiveness" is not a helpful metric of neurotechnology safety or utility. Scientists and engineers developing devices should take a holistic view of how the device affects the patient's overall health.

\section{PRECONCEPTION: BCIS WILL NOT BE CLINICALLY USEFUL UNTIL THEY CAN EXTRACT MORE INFORMATION}

Over the past several decades, several groups working on primate motor neurophysiology have found that the single-unit, ensemble and local field potential activity of motor areas in the brain can be "decoded" to yield information about a wide variety of motor parameters: not only two and three-dimensional end-point (i.e., hand) trajectory, but also muscle contraction states, pattern generator and spinal synergy activation states, joint kinematics, velocity and acceleration, attentional states, sequence and planning features and somatosensory fields (Carpenter et al., 1999; Matsuzaka et al., 2007; Stark et al., 2007; Umilta et al., 2007; Scott, 2008; Zach et al., 2008; Griffin et al., 2009; Vargas-Irwin et al., 2010; Pruszynski et al., 2011; Saleh et al., 2012; Addou et al., 2014; Crowe et al., 2014; Kirsch et al., 2014). Information rate, following the conventions initially developed by Claude Shannon, have been one popular way of quantifying BCI performance (Baranauskas, 2014). While elucidating from a basic neurophysiology perspective, these approaches do not axiomatically translate into device development and clinical utility. Information transfer metrics that elucidate how single neurons transform sensory and motor phenomena (Rieke et al., 1997), tend to devolve into unhelpful distortions of more appropriate performance metrics (such as task completion time or validated daily living functional measures; Peckham et al., 2001). From a practical engineering perspective it would be far better to have one or two degrees of freedom that could be decoded in a fast, reliable, technician-free manner, than seven degrees of freedom that were unreliable and required considerable external supervision to derive (Peckham et al., 2001; Rupp, 2014). While entropy rates can be constructed so as to include reliability as a feature, they are usually not considered in this manner. Another important feature to consider in addition to reliability is subjective effort. In principle, even one's heart rate could be used as input to a BCI: clearly such a tactic would require considerable mental focus and would be confounded by environmental distractions (e.g., accidentally launching oneself in a heart-rate driven wheelchair upon hearing a horn honk). The farther one moves from the neocortical areas driving voluntary movement, the more challenging it is for a patient to acquire and sustain control. While direct $\mathrm{BCIs}$ have been touted for their ability to yield more degrees-of-freedom and signal complexity, their greatest benefit may in fact be the fact that voluntary modulation of signals recorded intracranially from motor areas is most akin to natural movement and hence is subjectively effortless for the human participant, much as it is for healthy humans moving their intact limbs. Conclusion: 
The quantity and complexity of information are limited metrics for BCI translation to clinical application. BCIs will be clinically useful when they can extract information in a reliable and subjectively effortless manner with minimal calibration or technician supervision.

\section{PRECONCEPTION: HUMAN PILOT TRIALS FOR DIRECT BCIS MUST RELY ON VENTURE CAPITAL FUNDING OR RARE FEDERAL OPPORTUNITIES}

It usually takes 7 years and costs $\$ 40$ million to take a final medical device prototype from bench to bedside. It takes two to three years of preparation and nearly $\$ 6$ million just to launch an initial Investigational Device Exemption (IDE) trial. What exactly does this money pay for? One component is to salary support for consultants with regulatory expertise: this knowledge of the inner workings of the FDA, CE and other foreign equivalents, does not typically "live" inside academia. To have any hope of translational success, investigators must recruit regulatory colleagues who have successful track records of shepherding novel devices through the IDE process. The upfront $\$ 6$ million also pays for "freezing the design" of the device or fabrication process, establishing clean room Good Manufacturing Practices, and sending off device prototypes to existing, commercial "testing houses" that can systematically test the toxicity and biocompatibility of the device and its electrical safety in the hospital environment. While purposefully incorporating already-approved well-tested materials and fabrication techniques can reassure regulators, these agencies ultimately require these additional tests.

The organizational complexity and financial cost of this process does not fit into the typical R01 or non-NIH equivalents that sustain academic neuroscience laboratories. These leave translational investigators with few options. One is to appeal to special multi-center U01, Veteran's Affairs or other military-based (e.g., DARPA) multi-million dollar requests for applications. The FES Center in Cleveland, has been successful in following this non-commercial multi-center approach for their neuromuscular stimulator system to restore independent voluntary movement in veterans with spinal cord injury (Peckham et al., 1988). The Department of Defense may withdraw funds if performance metrics aren't met rendering it difficult to plan appropriately for multi-year trials. While the National Institutes of Health sponsors intramural clinical trials, there is not as extensive a track record for extramural ones devoted to novel devices. In terms of funding academic-industry partnerships, SBIRs and STTRs are simply not at the scale of $\$ 6$ million needed.

The other option is to create a startup neurotechnology company and apply for funding from angel investors and venture capitalists. Except for very simple mechanical based neurotechnologies (such as a new kind of shunt), few BCI technologies are at a stage of commercialization potential that render them appropriate for risk-averse investors. A pilot trial for a BCI may simply not make any investment sense for the typical venture capital funding model (Ford and Nelsen, 2014). If anything, a promising BCI would be more ripe for VC funding after a pilot trial demonstrated safety and efficacy.

This investigator therefore proposes that federal agencies create new funding mechanisms that fill this gap. These funds would help investigators set up clean room fabrication facilities and cover the cost of the numerous regulatory-required tests for the device. Ideally, all members on the study sections for this putative new mechanism would have some kind of clinical trial expertise, including physicians, FDA regulators, and scientists or engineers who have already successfully run human trials on their own. Given the scale and duration of the funding, and the fact that sudden withdrawal of funding in the middle of a trial could potentially risk patient health, thought should be given to render this new mechanism "sequester-proof" should political forces slash funding. Since industry investors would be the financial beneficiaries of these trials, one approach would be to set aside transparent pools donated by industry explicitly allocated for this novel translational funding mechanism. Agencies could make this financially worthwhile if they could eliminate waste and streamline the process, thus increasing the amount of return for each dollar invested on pilot trial development. By pulling actual FDA regulatory officials into these novel study sections, investigators and future investors would also reap enormous benefit in the regulatory process with this "insider" knowledge. Rather than have each BCI team muddle through the prototype, clean room, standard biosafety/bioelectrical testing, by itself, this mechanism would have its own streamlined process. Conclusion: Leaders in government, industry and academia should forge new funding mechanisms that can help investigators shepherd promising BCI technologies into pilot clinical trials to a stage where traditional existing $\mathrm{VC}$ and industry funding make sense and the chances of commercialization were greater.

\section{PRECONCEPTION: IF A BCI WERE SAFE AND EFFECTIVE, MARKET FORCES WILL AUTOMATICALLY PROPEL IT TOWARDS WIDESPREAD CLINICAL USE}

Many good ideas may never end up helping patients due to a variety of reasons as they may not be marketable or may be badly marketed (Vecht et al., 2010). Despite clear demonstration of the safety and efficacy of the FreeHand functional electrical stimulation system to help patients with spinal cord injury (Peckham et al., 1988; Taylor et al., 2002), the small company commercializing it (NeuroControl) went out of business before meeting clinical demand. Scientists seeking to bring a promising neurotechnology from bench to bedside would do well to understand why certain efforts flounder and why others succeed (de Ana et al., 2013; Pisano, 2006; Galloway, 2007; Fletcher and Bourne, 2012). Neurotechnology ventures need to involve business experts early (Leuthardt, 2013) to ensure they can navigate issues of patents, pricing, reimbursement, and multi-year alliances (Pangarkar and Hutmacher, 2003; Bergsland et al., 2014). Inventors must recognize the importance of skilled management (Burns et al., 2009), and have realistic expectations of how commercialization unfolds (Galloway, 2007; Fletcher and Bourne, 2012). Translational scientists must learn that: what drives science does not drive business, there is no single path to commercialization, "research" and "development" are very different phases, the market may not exist at the outset, and that customers are the "ultimate peer review" (Fletcher and Bourne, 2012). Conclusion: While having a strong safety and efficacy profile is necessary 
for a medical device, it is not sufficient to reach patients in need. To reach patients, devices must be supported by skilled management in both startup and established biotechnology companies.

\section{PRECONCEPTION: THE MARKET FOR NEUROSCIENCE MEDICAL DEVICE APPLICATIONS IS TOO HETEROGENEOUS AND SMALL TO BE WORTH THE INVESTMENT}

Any business from a Fortune 500 company to a corner bodega can be run poorly or well: the fact that there is more than one company manufacturing cochlear implants, for a market of less than a million patients, is testament to the fact that a device with demonstrable safety and efficacy can be financially sustainable. Furthermore, both DBS and cochlear implants are designed to improve quality of life: patients are not expected to die directly from deafness or tremor. Conclusion: To reach and benefit patients, safe and effective technologies must be brought to market by visionary entrepreneurs who have excellent management skills and a deep understanding of the clinical neuroscience landscape.

\section{PRECONCEPTION: THE BRAIN IS TOO COMPLEX: ANY MEDICAL DEVICE CANNOT SUCCEED UNTIL THE BRAIN IS BETTER UNDERSTOOD}

While cochlear and auditory-brainstem implants leverage neuroanatomical tonotopy to "play" neural structures, the fundamental mechanism of deep brain stimulators for movement disorders remains a source of controversy. Medicine is replete with countless treatments that are used daily to successfully improve human health despite the mechanism of these treatments not being understood. The efficacy of medical interventions is established empirically rather than mechanistically. Hundreds of medications are used to treat brainbased conditions (such as schizophrenia and epilepsy) despite our limited knowledge about the pathophysiology of these conditions or how particular medications exercise their effects. Conclusion: Neurotechnoloogy that can concretely help people can be financially remunerative even despite our incomplete knowledge of the human brain. Companies can "do well by doing good" by focusing on concrete quality of life outcome measures rather than relying on a mechanistic understanding of neurobiology.

\section{PRECONCEPTION: THE TIME TO APPROACH CLINICIANS AND PATIENTS WHEN CONSIDERING HUMAN APPLICATIONS OF DIRECT BCI OR OTHER NEUROTECHNOLOGIES IS ONLY AFTER THE TECHNOLOGY ITSELF IS FINALIZED AND ANIMAL STUDIES ARE COMPLETED}

Development of the Utah array from a research tool restricted to animal investigation to a clinical intervention in a pilot trial for human patients, benefited from close, friendly collaboration between engineers designing the device within industry and academic neurosurgeons. By literally handing prototypes to experienced surgeons to test in animal models and human cadavers, engineers could gain immediate feedback about helpful or limiting design features that no amount of bench work could reveal (Suner et al., 2005; Som et al., 2014). Conclusion: Scientists should engage physicians, surgeons and patients much earlier in the design cycle.

\section{RECOMMENDATIONS FOR IMPROVING NEUROTECHNOLOGY DEVELOPMENT}

BCI translation can be accelerated by tightening the design cycle with close collaboration between engineers, scientists, surgeons, regulatory experts, and clinicians.

Basic scientists and engineers are urged to never assume what risk-safety profiles are needed for a device to help a person: they should query physicians, surgeons and even potential beneficiaries and their families, sooner rather than later to ascertain the medical context, and should focus their energies on making the device truly useful.

Engineers and scientists are encouraged to visit the patients whose their technology is intended to help and understand what solutions they have deployed now to inform what the new technology must outperform.

Considerations of safety must be holistic and take into account the overall clinical context: non-invasive devices are not necessarily safer or more practical than invasive ones.

While metrics such as "degrees of freedom" and "entropy bit rate" have their utility, to facilitate clinical translation, device developers should focus on increasing device reliability, decreasing subjective effort, reducing calibration and minimizing technician supervision.

Leadership in government and industry are encouraged to consider alternate funding mechanisms that can shepherd technologies farther towards commercialization.

Scientists, surgeons, engineers and physicians seeking to commercialize promising neurotechnologies should recruit entrepreneurs with considerable management skill and a track record of shepherding devices into profitable commercialization.

\section{ACKNOWLEDGMENTS}

The author would like to thank John Donoghue, Mikhail Shapiro, Nandini Murthy, and Kurt Dasse for their helpful input and insights over the past two decades, and to Abdolmohammed Rostami and Thomas Jefferson University for financial support.

\section{REFERENCES}

Addou, T., Krouchev, N., and Kalaska, J. F. (2014). Motor cortex single-neuron and population contributions to compensation for multiple dynamic force fields. J. Neurophysiol. doi: 10.1152/jn.00094.2014. [Epub ahead of print].

Baranauskas, G. (2014). What limits the performance of current invasive brain machine interfaces? Front. Syst. Neurosci. 8:68. doi: 10.3389/fnsys.2014.00068

Barrese, J. C., Rao, N., Paroo, K., Triebwasser, C., Vargas-Irwin, C., Franquemont, L., et al. (2013). Failure mode analysis of silicon-based intracortical microelectrode arrays in non-human primates. J. Neural Eng. 10:066014. doi: 10. 1088/1741-2560/10/6/066014

Bergsland, J., Elle, O. J., and Fosse, E. (2014). Barriers to medical device innovation. Med. Devices (Auckl) 7, 205-209. doi: 10.2147/MDER.S43369

Burns, L. R., Housman, M. G., and Robinson, C. A. (2009). Market entry and exit by biotech and device companies funded by venture capital. Health Aff. (Millwood) 28, w76-w86. doi: 10.1377/hlthaff.28.1.w76

Carpenter, A. F., Georgopoulos, A. P., and Pellizzer, G. (1999). Motor cortical encoding of serial order in a context-recall task. Science 283, 1752-1757. doi: 10. 1126/science.283.5408.1752

Ceyssens, F., van Kuyck, K., Vande Velde, G., Welkenhuysen, M., Stappers, L., Nuttin, B., et al. (2013). Resorbable scaffold based chronic neural electrode arrays. Biomed. Microdevices 15, 481-493. doi: 10.1007/s10544-013-9748-x

Collinger, J. L., Wodlinger, B., Downey, J. E., Wang, W., Tyler-Kabara, E. C., Weber, D. J., et al. (2013). High-performance neuroprosthetic control by an individual with tetraplegia. Lancet 381, 557-564. doi: 10.1016/S0140-6736(12)61816-9 
Crowe, D. A., Zarco, W., Bartolo, R., and Merchant, H. (2014). Dynamic representation of the temporal and sequential structure of rhythmic movements in the primate medial premotor cortex. J. Neurosci. 34, 11972-11983. doi: 10. 1523/JNEUROSCI.2177-14.2014

de Ana, F. J., Umstead, K. A., Phillips, G. J., and Conner, C. P. (2013). Value driven innovation in medical device design: a process for balancing stakeholder voices. Ann. Biomed. Eng. 41, 1811-1821. doi: 10.1007/s10439-013-0779-5

Djourno, A., and Eyries, C. (1957). Auditory prosthesis by means of a distant electrical stimulation of the sensory nerve with the use of an indwelt coiling. Presse Med. 65, 1417.

Dolan, K., Martens, H. C., Schuurman, P. R., and Bour, L. J. (2009). Automatic noise-level detection for extra-cellular micro-electrode recordings. Med. Biol. Eng. Comput. 47, 791-800. doi: 10.1007/s11517-009-0494-4

Edgington, R. J., Thalhammer, A., Welch, J. O., Bongrain, A., Bergonzo, P., Scorsone, E., et al. (2013). Patterned neuronal networks using nanodiamonds and the effect of varying nanodiamond properties on neuronal adhesion and outgrowth. J. Neural Eng. 10:056022. doi: 10.1088/1741-2560/10/5/056022

Fletcher, A. C., and Bourne, P. E. (2012). Ten simple rules to commercialize scientific research. PLoS Comput. Biol. 8:e1002712. doi: 10.1371/journal.pcbi. 1002712

Flint, R. D., Wright, Z. A., Scheid, M. R., and Slutzky, M. W. (2013). Long term, stable brain machine interface performance using local field potentials and multiunit spikes. J. Neural Eng. 10:056005. doi: 10.1088/1741-2560/10/5/056005

Ford, D., and Nelsen, B. (2014). The view beyond venture capital. Nat. Biotechnol. 32, 15-23. doi: 10.1038/nbt.2780

Frewin, C. L., Locke, C., Saddow, S. E., and Weeber, E. J. (2011). Single-crystal cubic silicon carbide: an in vivo biocompatible semiconductor for brain machine interface devices. Conf. Proc. IEEE Eng. Med. Biol. Soc. 2011, 2957-2960. doi: 10. 1109/IEMBS.2011.6090582

Galloway, R. L. (2007). Found in translation; from the laboratory to the operating room to the market. Conf. Proc. IEEE Eng. Med. Biol. Soc. 2007, 5162-5165. doi: 10.1109/IEMBS.2007.4353504

Griffin, D. M., Hudson, H. M., Belhaj-Saif, A., and Cheney, P. D. (2009). Stability of output effects from motor cortex to forelimb muscles in primates. J. Neurosci. 29, 1915-1927. doi: 10.1523/JNEUROSCI.4831-08.2009

Hampson, R. E., Song, D., Opris, I., Santos, L. M., Shin, D. C., Gerhardt, G. A., et al. (2013). Facilitation of memory encoding in primate hippocampus by a neuroprosthesis that promotes task-specific neural firing. J. Neural Eng. 10:066013. doi: 10.1088/1741-2560/10/6/066013

Hochberg, L. R., Bacher, D., Jarosiewicz, B., Masse, N. Y., Simeral, J. D., Vogel, J., et al. (2012). Reach and grasp by people with tetraplegia using a neurally controlled robotic arm. Nature 485, 372-375. doi: 10.1038/nature11076

Hochberg, L. R., Serruya, M. D., Friehs, G. M., Mukand, J. A., Saleh, M., Caplan, A. H., et al. (2006). Neuronal ensemble control of prosthetic devices by a human with tetraplegia. Nature 442, 164-171. doi: 10.1038/nature04970

Kirsch, E., Rivlis, G., and Schieber, M. H. (2014). Primary motor cortex neurons during individuated finger and wrist movements: correlation of spike firing rates with the motion of individual digits versus their principal components. Front. Neurol. 5:70. doi: 10.3389/fneur.2014.00070

Lebedev, M. (2014). Brain-machine interfaces: an overview. Transl. Neurosci. 5, 99110. doi: 10.2478/s13380-014-0212-z

Leuthardt, E. C. (2013). Developing a new model for the invention and translation of neurotechnologies in academic neurosurgery. Neurosurgery 72 (Suppl. 1), 182-192. doi: 10.1227/NEU.0b013e318270cfec

Macherey, O., and Carlyon, R. P. (2014). Cochlear implants. Curr. Biol. 24, R878R884. doi: 10.1016/j.cub.2014.06.053

Matsuzaka, Y., Picard, N., and Strick, P. L. (2007). Skill representation in the primary motor cortex after long-term practice. J. Neurophysiol. 97, 1819-1832. doi: 10.1152/jn.00784.2006

Moxon, K. A., Hallman, S., Aslani, A., Kalkhoran, N. M., and Lelkes, P. I. (2007). Bioactive properties of nanostructured porous silicon for enhancing electrode to neuron interfaces. J. Biomater. Sci. Polym. Ed. 18, 1263-1281. doi: 10. $1163 / 156856207782177882$

Pangarkar, N., and Hutmacher, D. W. (2003). Invention and business performance in the tissue-engineering industry. Tissue Eng. 9, 1313-1322. doi: 10. 1089/10763270360728224

Peckham, P. H., Keith, M. W., and Freehafer, A. A. (1988). Restoration of functional control by electrical stimulation in the upper extremity of the quadriplegic patient. J. Bone Joint Surg. Am. 70, 144-148.
Peckham, P. H., Keith, M. W., Kilgore, K. L., Grill, J. H., Wuolle, K. S., Thrope, G. B., et al. (2001). Efficacy of an implanted neuroprosthesis for restoring hand grasp in tetraplegia: a multicenter study. Arch. Phys. Med. Rehabil. 82, 13801388. doi: 10.1053/apmr.2001.25910

Perge, J. A., Zhang, S., Malik, W. Q., Homer, M. L., Cash, S., Friehs, G., et al. (2014). Reliability of directional information in unsorted spikes and local field potentials recorded in human motor cortex. J. Neural Eng. 11:046007. doi: 10. 1088/1741-2560/11/4/046007

Pisano, G. P. (2006). Can science be a business? Lessons from biotech. Harv. Bus. Rev. 84, 114-124.

Prasad, A., Xue, Q. S., Dieme, R., Sankar, V., Mayrand, R. C., Nishida, T., et al. (2014). Abiotic-biotic characterization of Pt/Ir microelectrode arrays in chronic implants. Front. Neuroeng. 7:2. doi: 10.3389/fneng.2014.00002

Pruszynski, J. A., Kurtzer, I., Nashed, J. Y., Omrani, M., Brouwer, B., and Scott, S. H. (2011). Primary motor cortex underlies multi-joint integration for fast feedback control. Nature 478, 387-390. doi: 10.1038/nature10436

Rieke, F., Warland, D., de Ruyter van Stevenick, R., and Bialek, W. (1997). Spikes. Exploring the Neural Code. Cambridge, MA: MIT Press.

Rupp, R. (2014). Challenges in clinical applications of brain computer interfaces in individuals with spinal cord injury. Front. Neuroeng. 7:38. doi: 10.3389/fneng. 2014.00038

Saleh, M., Takahashi, K., and Hatsopoulos, N. G. (2012). Encoding of coordinated reach and grasp trajectories in primary motor cortex. J. Neurosci. 32, 1220-1232. doi: 10.1523/JNEUROSCI.2438-11.2012

Sanchez, J. C., Alba, N., Nishida, T., Batich, C., and Carney, P. R. (2006). Structural modifications in chronic microwire electrodes for cortical neuroprosthetics: a case study. IEEE Trans. Neural Syst. Rehabil. Eng. 14, 217-221. doi: 10. 1109/TNSRE.2006.875581

Sankar, T., Lipsman, N., and Lozano, A. M. (2014). Deep brain stimulation for disorders of memory and cognition. Neurotherapeutics 11, 527-534. doi: 10 . 1007/s13311-014-0275-0

Scott, S. H. (2008). Inconvenient truths about neural processing in primary motor cortex. J. Physiol. 586, 1217-1224. doi: 10.1113/jphysiol.2007.146068

Sellers, E. W., Vaughan, T. M., and Wolpaw, J. R. (2010). A brain-computer interface for long-term independent home use. Amyotroph. Lateral Scler. 11, 449-455. doi: 10.3109/17482961003777470

Som, A., Charanya, T., Linderman, S. W., and Siegel, J. S. (2014). Bridging the gap between invention and commercialization in medical devices. Nat. Biotechnol. 32, 1063-1065. doi: 10.1038/nbt.3041

Sommakia, S., Rickus, J. L., and Otto, K. J. (2009). Effects of adsorbed proteins, an antifouling agent and long-duration DC voltage pulses on the impedance of silicon-based neural microelectrodes. Conf. Proc. IEEE Eng. Med. Biol. Soc. 2009, 7139-7142. doi: 10.1109/IEMBS.2009.5332456

Stacey, W. C., and Litt, B. (2008). Technology insight: neuroengineering and epilepsy-designing devices for seizure control. Nat. Clin. Pract. Neurol. 4, 190 201. doi: 10.1038/ncpneuro0750

Stark, E., Drori, R., Asher, I., Ben-Shaul, Y., and Abeles, M. (2007). Distinct movement parameters are represented by different neurons in the motor cortex. Eur. J. Neurosci. 26, 1055-1066. doi: 10.1111/j.1460-9568.2007. 05711.x

Suner, S., Fellows, M. R., Vargas-Irwin, C., Nakata, G. K., and Donoghue, J. P. (2005). Reliability of signals from a chronically implanted, silicon-based electrode array in non-human primate primary motor cortex. IEEE Trans. Neural Syst. Rehabil. Eng. 13, 524-541. doi: 10.1109/TNSRE.2005.857687

Taherian, S., Selitskiy, D., Pau, J., Davies, T. C., and Owens, R. G. (2014). Training to use a commercial brain-computer interface as access technology: a case study. Disabil. Rehabil. Assist. Technol. 1, 1-6. doi: 10.3109/17483107.2014. 967313.

Taylor, P., Esnouf, J., and Hobby, J. (2002). The functional impact of the Freehand System on tetraplegic hand function. Clinical results. Spinal Cord 40, 560-566. doi: 10.1038/sj.sc.3101373

Umilta, M. A., Brochier, T., Spinks, R. L., and Lemon, R. N. (2007). Simultaneous recording of macaque premotor and primary motor cortex neuronal populations reveals different functional contributions to visuomotor grasp. J. Neurophysiol. 98, 488-501. doi: 10.1152/jn.01094.2006

Vargas-Irwin, C. E., Shakhnarovich, G., Yadollahpour, P., Mislow, J. M., Black, M. J., and Donoghue, J. P. (2010). Decoding complete reach and grasp actions from local primary motor cortex populations. J. Neurosci. J30, 9659-9669. doi: 10. 1523/JNEUROSCI.5443-09.2010 
Vecht, J. A., von Segesser, L. K., Ashrafian, H., Rao, C., Skapinakis, P., Saso, S., et al. (2010). Translation to success of surgical innovation. Eur. J. Cardiothorac. Surg. 37, 613-625. doi: 10.1016/j.ejcts.2009.08.032

Wang, D., Zhang, Q., Li, Y., Wang, Y., Zhu, J., Zhang, S., et al. (2014). Long-term decoding stability of local field potentials from silicon arrays in primate motor cortex during a 2D center out task. J. Neural Eng. 11:036009. doi: 10.1088/17412560/11/3/036009

Wu, W., Black, M. J., Mumford, D., Gao, Y., Bienenstock, E., and Donoghue, J. P. (2004). Modeling and decoding motor cortical activity using a switching Kalman filter. IEEE Trans. Biomed. Eng. 51, 933-942. doi: 10.1109/TBME.2004. 826666

Zach, N., Inbar, D., Grinvald, Y., Bergman, H., and Vaadia, E. (2008). Emergence of novel representations in primary motor cortex and premotor neurons during associative learning. J. Neurosci. 28, 9545-9556. doi: 10.1523/JNEUROSCI.196508.2008
Conflict of Interest Statement: The author declares that the research was conducted in the absence of any commercial or financial relationships that could be construed as a potential conflict of interest.

Received: 14 October 2014; accepted: 10 November 2014; published online: 02 December 2014.

Citation: Serruya MD (2014) Bottlenecks to clinical translation of direct brain-computer interfaces. Front. Syst. Neurosci. 8:226. doi: 10.3389/fnsys.2014.00226 This article was submitted to the journal Frontiers in Systems Neuroscience.

Copyright (C) 2014 Serruya. This is an open-access article distributed under the terms of the Creative Commons Attribution License (CC BY). The use, distribution and reproduction in other forums is permitted, provided the original author(s) or licensor are credited and that the original publication in this journal is cited, in accordance with accepted academic practice. No use, distribution or reproduction is permitted which does not comply with these terms. 